Научная статья

УДК 316.74

DOI: $10.17213 / 2075-2067-2021-5-21-26$

\title{
ОПЕРАЦИОНАЛИЗАЦИЯ ПОНЯТИЯ ЭФФЕКТИВНОСТИ ГОСУДАРСТВЕННОГО УПРАВЛЕНИЯ ВЫСШИМ ОБРАЗОВАНИЕМ
}

\section{Тембот Батырбиевич Берсиров}

\section{Майкопский государственный технологический университет, Майкоп, Россия tbersey@mail.ru, ORCID:0000-0003-1551-2706}

\begin{abstract}
Аннотация. Целью является проведение операционализации понятия эффективности государственного управления высшим образованием для определения эмпирических индикаторов как инструментов социологического измерения успешности реализуемой в настоящеее время реформы высшей школь.
\end{abstract}

Методология основывается на неоинституцииональной парадигме, которая обеспечивает возможность субъектного и институционального измерения эффективности государственного управления выстим образованием.

Результаты. Важнейшим итоговым результатом проведенного анализа по заявленной проблематике является последовательная операционализация понятия эффективности государственного управления высшим образованием, благодаря которой нам удалось выйти на решения, имеющие как теоретическое, так и практическое значение. В теоретическом аспекте даны определения ключевым понятиям, смежным с тем, которое сформулировано в титуле данной статьи, но актуальным относительно создания концепции, направленной на выстраивание методологического основания для изучения эффективности государственного управления высшей школой. К их числу относятся «эффективность», "эффективность государственного управления», «эффективность государственного управления высшей школой». В прикладном аспекте очень важно вылелить результат, заданный иелью предлагаемой к рассмотрению статьи. Речь идет об определении эмпирических индикаторов, посредством которых можно было бы измерить реальную, а не декларативную эффективность. Актуальность подобного измерения обуславливается тем, что в некоммерческом секторе достижение эффективности принципиально не сводимо к показателям монетарного характера, а следовательно, необходимы верифицированнье переменные, посредством которых эффективность управленческих действий может быть подтверждена или опровергнута.

Перспективы исследований авторы усматривают в применении определенных эмпирических индикаторов в рамках массового сочиологического опроса для исследования иелевых ориентаций, ценностей, интересов акторов институционального пространства высшей школьл.

Ключевые слова: высшее образование, эффективность, эффективность государственного управления, ресурсы, эмпирические индикаторы, риски недостижения эффективности

Для цитирования: Берсиров Т. Б. Операционализаџия понятия эффективности государственного управления высшим образованием // Вестник Южно-Российского государственного технического университета. Серия: Социально-экономические науки. 2021. T. 14, №5. C. 21-26. http://dx.doi.org/10.17213/2075-2067-2021-5-21-26.

(C) Берсиров Т.Б., 2021 
Original article

\title{
OPERATIONALIZATION OF THE CONCEPT OF EFFICIENCY OF STATE MANAGEMENT OF HIGHER EDUCATION
}

\author{
Tembot B. Bersirov \\ Maikop State Technological University, Maikop, Russia \\ tbersey@mail.ru,ORCID:0000-0003-1551-2706
}

\begin{abstract}
The purpose of the study is to operationalize the concept of the effectiveness of public administration of higher education in order to determine empirical indicators as tools for sociological measurement of the success of the currently implemented reform of higher education.

The methodological basis in general theoretical terms is based on the neo-institutional paradigm, which provides the possibility of subjective and institutional measurement of the effectiveness of public administration of higher education.

Research result. The most important final result of the analysis on the stated problems is the consistent operationalization of the concept of the effectiveness of public administration of higher education, thanks to which we were able to reach solutions that have both theoretical and practical significance. In the theoretical aspect, definitions are given to key concepts that are related to the one formulated in the title of this article, but relevant to the creation of a concept aimed at building a methodological basis for studying the effectiveness of public administration in higher education. These include "efficiency», "efficiency of public administration», "efficiency of public administration of higher education». In the applied aspect, it is very important to highlight the result set by the purpose of the proposed article. It is about identifying empirical indicators that can be used to measure real, rather than declarative, performance. The relevance of this measurement is due to the fact that in the non-profit sector, the achievement of efficiency is fundamentally not reduced to monetary indicators, and therefore, verified variables are needed, through which the effectiveness of management actions can be confirmed or refuted.
\end{abstract}

The prospect of the study is for further research in the application of certain empirical indicators in the framework of a mass sociological survey to study the target orientations, values, and interests of actors in the institutional space of higher education.

Keywords: higher education, efficiency, efficiency of public administration, resources, empirical indicators, risks of failure to achieve efficiency

For citation: Bersirov T. B. Operationalization of the concept of efficiency of state management of higher education // Bulletin of the South Russian State Technical University. Series: Socio-economic Sciences. 2021; 14 (5): 21-26. (In Russ.). http://dx.doi.org/10.17213/2075-2067-2021-5-21-26.

Введение. В настоящее время проводится реформа в системе образования. Реформаторские процессы коснулись и самого верхнего звена системы российского образования - высшей школы. Главным последствием изменений стало радикальное преобразование всех принципов и традиций, на основе которых высшее образование функционировало в дореформенный период. Совер- шенно очевидно, что на столь радикальные усилия инициаторов указанных процессов могло подвергнуть остро негативное восприятие эффективности работы высшей школы. Еще с начала 90-х годов прошлого столетия в общественном и научном дискурсе поднимались проблемы о том, что российские вузы работают вразрез с основными требованиями времени, уступают основным пот- 
ребностям эпохи, низко оцениваются с точки зрения результативности основными акторами образовательного пространства: студентами, преподавателями, администрацией вуза, а также всеми заинтересованными сторонами, в числе которых чаще всего упоминались работодатели. Проходящие в настоящее время реформы нацелены в первую очередь на повышение эффективности образовательной деятельности российских вузов [2; 4; 10]. Однако результаты реформы получают крайне неоднозначную во многих своих проявлениях, критичную оценку. В связи с этим возникает вопрос: эта неоднозначность и эта критичность обусловлены проблемами адаптации к новой образовательной реальности, которая остро переживается всеми акторами без исключения, или в основе сомнений относительно проводимой реформы лежит убежденность в ее неэффективности? Этот вопрос актуализирует проведение эмпирических исследований, которые периодически осуществляются специалистами по социологии образования, но чаще всего самой же администрацией вузов. Мы полагаем, кто бы эти исследования ни проводил, они не будут иметь должной валидности, если под них не выстроить соответствующую задачам теоретико-методологическую платформу. В свете сказанного целью исследования является проведение операционализации понятия эффективности государственного управления высшим образованием для определения эмпирических индикаторов как инструментов социологического измерения успешности реализуемой в настоящее время реформы высшей школы.

Понятие эффективности в рамках сложившегося теоретического дискурса. Термин «эффективность» в научный оборот вводит Д. Рикардо, рассматривая его как соотношение между затраченными ресурсами и полученным результатом [6]. Эта трактовка становится в научной традиции господствующей на длительный промежуток времени, формируя оценочные установки для ее интерпретации [1]. Однако в конце XX века среди экономистов развернулась дискуссия вокруг этого понятия, т.к. были предложены иные когнитивные координаты. Причиной изменения традиционных представлений оказалось применение менеджеристских инструментов в управлении некоммерческим сектором. Это обусловило резкое расширение дискурсивного пространства, т.к. его участниками стали не только экономисты, как прежде, но и представители иных наук: социологии, политологии, психологии, педагогики, юриспруденции и других. В результате обсуждения его участники разошлись на три дискурсивные площадки, где удалось прийти хотя бы к относительной согласованности в позициях [8].

Далее мы рассмотрим основные результаты представленной дискуссии, чтобы затем связать их с конструктом эффективности государственного управления высшим образованием.

В рамках первого подхода понимание эффективности нацеливается на достижение желаемого результата [5]. Безусловно, это крайне субъективная интерпретация понятия, и ее трудно воспринять из-за невозможности подобрать объективные критерии для оценивания. В подобных терминологических границах эффективность замеряется через арифметическую удовлетворенность социальных акторов. Она может быть рабочей в системе высшего образования, когда оно отождествляется с частными образовательными услугами. Второй подход сформировался на прежних позициях, характерных для экономической науки. Его представители рассчитывают эффективность из соотношения полученного результата и вложенного объема ресурсов [3]. Если этот подход применять к высшему образованию, то в основу измерения должны быть положены количественные показатели как главный индикатор достижения эффективности. Что касается третьего подхода, то он стал подлинно инновационным, и его появление можно оценивать как приращение научного знания благодаря состоявшейся дискуссии. Его особенность состоит в том, что критерием эффективности выступает достижение цели, поставленной перед организацией, если она была достигнута с таким количеством ресурсов, которое признано разумным и оправданным относительно специфики определенного вида деятельности [9]. В этом подходе мы видим разумный баланс субъективного и объективного. Для системы высшего образования данный подход может быть применим в том случае, если работают 
механизмы академической оценки, то есть имеются такие институциональные связи между акторами, которые позволяют формировать конвенциональное пространство смыслов.

Таким образом, по нашему мнению, эффективность представляет собой наиболее разумное с точки зрения конвенциональной позиции основных акторов применение ресурсов, направленных на достижение целей, которые признаются значимыми для социальных акторов институционального пространства и внешних целей, соизмеренных с функциями социального института.

Конструирование понятия эффективности государственного управления высшей школой. Данное выше определение эффективности в приложении к высшему образованию означает, что оно может быть измеренным как с внутренних позиций социальных акторов, так и с точки зрения экспертного мнения о достижении высшим образованием ожидаемых от него целей. Это означает, что нам необходимо определиться, какие целевые функции имеются у социального института высшего образования.

Объединим этот аспект с определением основного актора, ответственного за эффективное управление высшим образованием. Это государство, определяющее федеральные образовательные стандарты, нормативные акты в системе системе менеджмента качества, замещение на должностях высших руководителей администрации вузов и ряд других базовых нормативных рамок, выступающих фундаментальными основаниями для проведения интеракций между социальными акторами, обеспечивающими и реализующими образовательный процесс в высшей школе.

Именно государство ответственно в том числе и за целевые ориентиры развития высшего образования. Согласно статье 2 федерального закона «Об образовании» к ним относятся три ведущие цели: профессиональная подготовка, социализация студентов и научная деятельность. Таким образом, говоря об эффективности государственного управления высшей школой, необходимо вести речь о том, насколько в процессе управленческой деятельности достигаются указанные цели при оптимальном расходовании ресурсов.
Здесь необходимо сделать ряд пояснений. Институциональная сфера высшего образования имеет дело с продуктом особого качества. Создаваемая им ценность - «знания» - проявляется в форме научных инноваций или актуально значимой образовательной информации. В отличие от деятельности коммерческой организации, где первостепенному учету подлежат затраченные материальные ресурсы и производственное время, в высшей школе происходит сложная синергия вложенных усилий и полученных результатов, эффективность которых чаще всего не имеет прямой корреляции с материальными ресурсами и продолжительностью труда, да и оценена она может быть через неопределенное время и неопределенными субъектами (работодателями, выпускниками, пациентами, клиентами, коллегами и т.п.).

В подобном понимании главная проблема достижения эффективности заключается в гармонизации указанных в вышеприведенном определении представлений относительно его качественного содержания между тремя сторонами - социальным актором, организацией и социумом. Потенциально вероятное решение заложено в избранном нами теоретическом подходе. Ценность заявленной неоинституциональной методологии состоит в том, что она предоставляет возможность обосновать процессуальную сторону выхода на ожидаемые показатели эффективности и одновременно показывает универсальные для всех институциональных сфер перспективы решения проблем недостижения эффективности.

Общая позиция неоинституционализма - признание активной роли социальных акторов в осуществлении интеракций, но эта активность обладает известными границами, которые устанавливаются социальными институтами. Границы имеют условно-конвенциональную природу, что обеспечивает им наличие весьма сильного заряда ригидности. Они не меняются под воздействием кратковременных потребностей и до определенного момента даже способны проявлять устойчивость к социальным изменениям. Такое их своеобразие обеспечивает формирование стабильной социокультурной матрицы, которая выступает в роли фильтра, пропускающего через себя типового актора, готового реализовывать не только индивидуализиро- 
ванные интересы, но и групповые (организационные). Эффективность достигается благодаря тому, что деятельность социальных акторов содействует установлению институционального равновесия, их трансакционные издержки не ущемляют интересов других акторов, а целевая направленность обуславливается рациональным выбором.

Наибольший потенциал риска недостижения эффективности содержит отсутствие постулируемой рациональности в выборе целевых ориентаций и ресурсов для их достижения социальными акторами. Это может быть связано с отсутствием свободы в принятии решений, но в рамках неоинституционального подхода принято считать, что подобного рода проблема проистекает от так называемой ограниченной рациональности [7]. Под этим обычно понимается когнитивная неспособность из множества различных альтернатив выбрать именно ту, которая обусловит наиболее эффективную модель поведения. Это особенно актуально в первую очередь для некоммерческого сектора, т.к. результаты его функционирования менее прогнозируемы, чем деятельность коммерческих организаций. Еще в большей степени это верно в отношении оценивания результатов, поскольку они едва ли могут быть измерены посредством таких универсальных индикаторов, как деньги. Кроме того, как уже указывалось, значимость результата, а следовательно, и общая оценка эффективности видны только по истечении определенного времени, что ведет к запозданию в принятии значимых управленческих решений.

В результате проведенной работы мы можем дать итоговое определение эффективности государственного управления высшей школой. Это деятельность уполномоченных органов государственной власти, обеспечивающая достижение таких целей, как профессиональная подготовка, социализация студенчества и научные инновации при оптимальном расходе затрачиваемых на все перечисленное общественных ресурсов.

Заключение. В науке отсутствует единое понимание эффективности. Можно выделить, как минимум, три основных подхода, в соответствии с которыми эффективность оценивается как субъективно значимый ре- зультат, как превышение доходов над расходами, как достижение заданной цели с оптимальным расходованием ресурсов. Мы определяем эффективность высшего образования как наиболее разумное с точки зрения конвенциональной позиции основных акторов применение ресурсов, направленных на достижение целей, которые признаются значимыми для социальных акторов институционального пространства и внешних целей, соизмеренных с функциями института высшего образования. Главное затруднение в обеспечении эффективного государственного управления высшей школой состоит в том, чтобы преодолеть ограниченную рациональность и выбрать именно ту альтернативную модель управленческих действий, в результате которой высшая школа будет не только достигать поставленные перед нею цели, но и обеспечивать в процессе этого достижения оптимальные траты общественных ресурсов.

\section{Список источников}

1. Аврех Г.Л., Федоренко Н.П., Щукин Е.П. Затраты и результаты: беседы об экономике. М.: Наука, 1990. 192 с.

2. Воденко К. В. Перспективы государственного регулирования сферы высшего образования // Гуманитарий Юга России. 2016. №6. C. 211-220.

3. Друкер П. Менеджмент: задачи, обязанности, практика. М.: Вильямс, 2008. 992 с.

4. Кушлин В.К. Государственное управление научно-инновационным развитием. Новое в мировой практике. М.: Проспект, 2017. 272 c.

5. Парето В. Учебник политической экономии: пер. с фр.; предисл. В. С. Автономова. 2-е изд. М.: ИНФРА-М, 2018. 592 с.

6. Рикардо Д. Начала политической экономии и налогового обложения. М.: Эксмо, $2007.960 \mathrm{c}$.

7. Сергеев А.М. Взаимосвязь основных категорий неоинституционализма // Известия Уральского государственного экономического университета. 2004. №8. С. 24-30.

8. Штеле Е. А., Вечерковская О.Б. К вопросу о понятии «эффективность» // Экономический анализ: теория и практика. 2017. Т. 16. №5. C. 935-947. 
9. Rothbard M. Power and Market: Government and the Economy. Auburn: Institute for Humane Studies, 1970. 325 p.

10. Konstantin V. Vodenko. Problems and Perspectives of State Regulation of System of Education in the Context of Provision of Russia's National Security // International Journal of educational management. 2019. Vol. 33, Issue 3. P. 462-469.

\section{References}

1. Avreh G.L., Fedorenko N.P., Shhukin E.P. Zatraty i rezul'taty: besedy ob jekonomike [Costs and results: conversations about the economy]. Moscow: Nauka. 1990. 192. (In Russ.).

2. Vodenko K. V. Perspektivy gosudarstvennogo regulirovanija sfery vysshego obrazovanija [Prospects of state regulation of the sphere of higher education] // Gumanitarij Juga Rossii. 2016; (6): 211-220. (In Russ.).

3. Druker P. Menedzhment: zadachi, objazannosti, praktika [Management: tasks, responsibilities, practice]. Moscow: Vil'jams. 2008. 992. (In Russ.).

4. Kushlin V.K. Gosudarstvennoe upravlenie nauchno-innovacionnym razvitiem. Novoe v mirovoj praktike. Moscow: Prospekt, 2017. 272 p. (In Russ.).
5. Pareto V. Uchebnik politicheskoj jekonomii: per. s fr. / V. Pareto; predisl. V.S. Avtonomova. 2-e izd. [Textbook of political economy: trans. from the French V. Pareto; preface by V.S. Avtonomov. 2nd ed.]. Moscow: INFRA-M. 2018. 592. (In Russ.).

6. Rikardo D. Nachala politicheskoj jekonomii i nalogovogo oblozhenija [The beginnings of political economy and tax taxation]. Moscow: Jeksmo. 2007. 960. (In Russ.).

7. Sergeev A.M. Vzaimosvjaz' osnovnyh kategorij neoinstitucionalizma [Interrelation of the main categories of neo-institutionalism] Izvestija Ural'skogo gosudarstvennogo jekonomicheskogo universiteta [News of Ural State University of Economics]. 2004; (8): 24-30. (In Russ.).

8. Shtele E.A., Vecherkovskaja O.B. K voprosu o ponjatii «jeffektivnost'» [On the question of the concept of «efficiency»] Jekonomicheskij analiz: teorija i praktika [Economic analysis: theory and practice]. 2017; 16(5): 935-947. (In Russ.).

9. Rothbard M. Power and Market: Government and the Economy. Auburn: Institute for Humane Studies, 1970. 325 p.

10. Konstantin V. Vodenko. Problems and Perspectives of State Regulation of System of Education in the Context of Provision of Russia's National Security // International Journal of educational management. 2019. Vol. 33, Issue 3. P. $462-469$.

Статья поступила в редакиию 01.08.2021; одобрена после рецензирования 25.08.2021; принята к публикачии 15.09.2021.

The article was submitted on 01.08.2021; approved after reviewing on 25.08.2021; accepted for publication on 15.09.2021.

\section{ИНФОРМАЦИЯ ОБ АВТОРАХ}

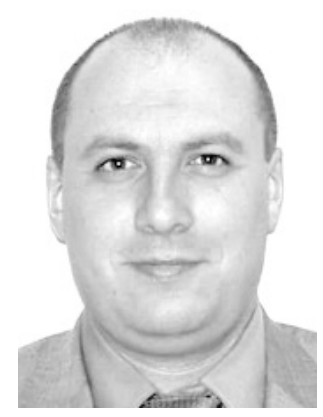

Берсиров Тембот Батырбиевич - кандидат социологических наук, доцент, Майкопский государственный технологический университет.

Россия, г. Майкоп, ул. Первомайская, 191

Tembot B. Bersirov - Candidate of Sociological Sciences, Associate Professor, Maikop State Technological University.

191 Pervomayskaya st., Maykop, Russia 